\title{
Prostate biopsy techniques and pre-biopsy prophylactic measures: variation in current practice patterns in the Netherlands
}

\author{
Sofie C. M. Tops ${ }^{1 *}$, Evert L. Koldewijn ${ }^{2}$, Diederik M. Somford ${ }^{3}$, Anita M. P. Huis ${ }^{4}$, Eva Kolwijck ,
} Heiman F. L. Wertheim ${ }^{1}$, Marlies E. J. L. Hulscher ${ }^{4}$ and J. P. Michiel Sedelaar ${ }^{5}$

\begin{abstract}
Background: The clinical landscape of prostate biopsy (PB) is evolving with changes in procedures and techniques. Moreover, antibiotic resistance is increasing and influences the efficacy of pre-biopsy prophylactic regimens. Therefore, increasing antibiotic resistance may impact on clinical care, which probably results in differences between hospitals. The objective of our study is to determine the (variability in) current practices of PB in the Netherlands and to gain insight into Dutch urologists' perceptions of fluoroquinolone resistance and biopsy related infections.

Methods: An online questionnaire was prepared using SurveyMonkey ${ }^{\oplus}$ platform and distributed to all 420 members of the Dutch Association of Urology, who work in 81 Dutch hospitals. Information about PB techniques and periprocedural antimicrobial prophylaxis was collected. Urologists' perceptions regarding pre-biopsy antibiotic prophylaxis in an era of antibiotic resistance was assessed. Descriptive statistical analysis was performed.

Results: One hundred sixty-one responses (38.3\%) were analyzed representing 65 (80.3\%) of all Dutch hospitals performing PB. Transrectal ultrasound guided prostate biopsy (TRUSPB) was performed in 64 (98.5\%) hospitals. $43.1 \%$ of the hospitals (also) used other image-guided biopsy techniques. Twenty-three different empirical prophylactic regimens were reported among the hospitals. Ciprofloxacin was most commonly prescribed (84.4\%). The duration ranged from one pre-biopsy dose (59.4\%) to 5 days extended prophylaxis. $25.2 \%$ of the urologists experienced ciprofloxacin resistance as a current problem in the prevention of biopsy related infections and $73.6 \%$ as a future problem.

Conclusions: There is a wide variation in practice patterns among Dutch urologists. TRUSPB is the most commonly used biopsy technique, but other image-guided biopsy techniques are increasingly used. Antimicrobial prophylaxis is not standardized and prolonged prophylaxis is common. The wide variation in practice patterns and lack of standardization underlines the need for evidence-based recommendations to guide urologists in choosing appropriate antimicrobial prophylaxis for PB in the context of increasing antibiotic resistance.
\end{abstract}

Keywords: Antibiotic prophylaxis, Antibiotic resistance, Healthcare research, Prostate biopsy, Transrectal biopsy

\footnotetext{
* Correspondence: sofie.tops@radboudumc.nl

'Department of Medical Microbiology, Radboud Center Infectious Diseases, Radboudumc, huispost 777, Geert Grooteplein Zuid 10, 6525, GA, Nijmegen, the Netherlands

Full list of author information is available at the end of the article
}

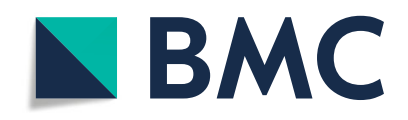

(- The Author(s). 2020 Open Access This article is licensed under a Creative Commons Attribution 4.0 International License, which permits use, sharing, adaptation, distribution and reproduction in any medium or format, as long as you give appropriate credit to the original author(s) and the source, provide a link to the Creative Commons licence, and indicate if changes were made. The images or other third party material in this article are included in the article's Creative Commons licence, unless indicated otherwise in a credit line to the material. If material is not included in the article's Creative Commons licence and your intended use is not permitted by statutory regulation or exceeds the permitted use, you will need to obtain permission directly from the copyright holder. To view a copy of this licence, visit http://creativecommons.org/licenses/by/4.0/. The Creative Commons Public Domain Dedication waiver (http://creativecommons.org/publicdomain/zero/1.0/) applies to the data made available in this article, unless otherwise stated in a credit line to the data. 


\section{Background}

In the Netherlands, prostate biopsy (PB) is performed in approximately 40,000 patients every year [1]. Biopsies are performed to diagnose prostate cancer and form the basis for further staging patients with prostate cancer in either low, intermediate or high risk prostate cancer groups. Random systematic transrectal ultrasound guided prostate biopsy (TRUSPB) has been the preferred method for years. The field of $\mathrm{PB}$, however, is undergoing rapid, significant change. Very recently, the European Association of Urology (EAU) guideline on prostate cancer has been updated [2]. An important modification in this guideline is the recommendation to also perform multiparametric magnetic resonance imaging (mpMRI) before $\mathrm{PB}$ in biopsy-naive patients and, when mPMRI is positive (i.e. PI-RADS $\geq 3$ ), to combine targeted and systematic biopsies. In addition, several more or less equivalent techniques are introduced to improve targeted biopsies [3]. These developments may have significant impact on the urological care provided in daily clinical practice, whereby it seems plausible that diagnostic differences exist between hospitals.

Moreover, (inter) national urological guidelines are unclear and lack standardization with regard to the recommended periprocedural prophylactic measures in $\mathrm{PB}$ [2, 4-7]. In Table 1 an overview of these guidelines is given [2, 4-7]. Guidelines strongly recommend the use of antimicrobial prophylaxis, generally with fluoroquinolones (FQ). The EAU guidelines on urological infections, however, states that the choice of regimen remains debatable [5]. An important reason for this is the increase in FQ resistant faecal flora, ranging from 10.6 to $92 \%$ between different countries, and $22 \%$ in the Netherlands, which is a potential threat for patients undergoing transrectal PB $[8,9]$.

In the guidelines, there is no cut-off point in the level of resistance at which FQ would be deemed ineffective and no recommendations about what equally effective other prophylactic regimens could be used [2, 4-7]. Therefore, urologists must assess the risk of carrying FQ resistant faecal flora and consider alternatives for each patient individually, which affects daily care and leads to variation in prostatic biopsy practices.

There are already signs that differences in PB care exist between health care providers. Studies from various countries (Sweden, Germany, Australia and New Zealand, Ireland and the United States) showed a lack of uniformity in PB techniques and pre-biopsy prophylaxis [10-15].

The objective of our study is to gain insight into current Dutch prostatic biopsy practices and to determine the variation in practice patterns among Dutch urologists in the context of the risk of post-biopsy infections. In addition urologists' perceptions of FQ resistance and biopsy related infections is assessed. It should be noted that at the time of our survey, the EAU guideline update was not published yet [2]. At that moment, guidelines stated to only perform mPMRI before repeat biopsy to allow targeted biopsies of suspicious lesions in addition to standard biopsies $[4,16]$.

Table 1 Overview of guidelines on the prevention of infectious complications after transrectal prostate biopsy

\begin{tabular}{|c|c|c|c|c|}
\hline Recommendations & $\begin{array}{l}\text { EAU guidelines on } \\
\text { prostate cancer [2] }\end{array}$ & $\begin{array}{l}\text { EAU guidelines on } \\
\text { urological infections [5] }\end{array}$ & AUA guidelines [4] & Dutch guidelines $[6,7]$ \\
\hline $\begin{array}{l}\text { First choice antimicrobial } \\
\text { prophylaxis }\end{array}$ & $\begin{array}{l}\text { Fluoroquinolones } \\
\text { with ciprofloxacin } \\
\text { being superior to } \\
\text { ofloxacin }\end{array}$ & $\begin{array}{l}\text { Debatable, most } \\
\text { commonly FQ are } \\
\text { applied }\end{array}$ & $\begin{array}{l}\text { Fluoroquinolones } \\
\text { or } 1 \mathrm{st} / 2 \mathrm{nd} / 3 \mathrm{rd} \text { gen. } \\
\text { Cephalosporin }\end{array}$ & Fluoroquinolones \\
\hline $\begin{array}{l}\text { Alternative antimicrobial } \\
\text { prophylaxis }\end{array}$ & Not mentioned & $\begin{array}{l}\text { Fosfomycin } \\
\text { trometamol }^{\mathrm{a}}\end{array}$ & $\begin{array}{l}\text { Co-trimoxazole } \\
\text { or Aminoglycoside } \\
\text { (Aztreonam) }\end{array}$ & $\begin{array}{l}\text { If recent culture shows } \\
\text { FQ resistance: antibiotics } \\
\text { based on the resistance } \\
\text { pattern, preferably co- } \\
\text { trimoxazole }\end{array}$ \\
\hline Duration of prophylaxis & Not mentioned & $\begin{array}{l}\text { Debatable, meta- } \\
\text { analysis by the } \\
\text { guideline panel } \\
\text { ongoing }\end{array}$ & $\leq 24 \mathrm{~h}$ & Single dose \\
\hline Timing of prophylaxis & Not mentioned & Not mentioned & $\begin{array}{l}\geq 1 \mathrm{~h} \text { before } \\
\text { prostate biopsy }\end{array}$ & Not mentioned \\
\hline $\begin{array}{l}\text { Culture-guided } \\
\text { prophylaxis }\end{array}$ & $\begin{array}{l}\text { Regional and local } \\
\text { resistance patterns } \\
\text { should be taken } \\
\text { into account when } \\
\text { deciding on the } \\
\text { choice of antibiotics }\end{array}$ & Mentioned $^{\mathrm{a}}$ & Not mentioned & $\begin{array}{l}\text { There is no indication } \\
\text { to routinely perform a } \\
\text { urine or rectum culture }\end{array}$ \\
\hline Topical preparation & $\begin{array}{l}\text { Rectal disinfection } \\
\text { with povidone-iodine } \\
\text { may be considered. }\end{array}$ & $\begin{array}{l}\text { Use rectal cleansing } \\
\text { with povidone-iodine }\end{array}$ & $\begin{array}{l}\text { No standard for } \\
\text { topical preparation } \\
\text { has been established }\end{array}$ & Not mentioned \\
\hline
\end{tabular}




\section{Methods}

\section{Design and study population}

In this observational study, a 5 min online questionnaire was prepared using SurveyMonkey platform. Pilot testing was performed by members of the research team. Thereafter, the online questionnaire was distributed by the Dutch Association of Urology (DUA) to all its members. From the 81 Dutch hospitals, a total of 420 urologists and residents were approached to gain insight into the practices in their hospital. In April 2018, all DUAmembers received an e-mail containing a unique link to complete the questionnaire. A reminder was sent after 2 weeks. Respondents were excluded from analysis if they only answered demographic questions or if the hospital of employment was unknown. Urologists from the Netherlands Antilles were also excluded from analysis.

All participants were informed about the voluntary nature of their participation and that their responses were kept confidential. They were able to access the questionnaire multiple times to allow for possible changes and completion at later times. No financial compensation was given in exchange for participation.

\section{Survey}

The survey consisted of three parts (25 items), and mainly multiple-choice questions were used. In the first part (five items) general information was collected regarding gender, position, number of years working in the current position, hospital name and location.

The second part consisted of 12 questions about biopsy technique and pre-prostate biopsy patient preparation. More specifically, urologists were asked about the route of $\mathrm{PB}$, type(s) of procedural imaging guidance, number of biopsy cores, whether prophylactic antibiotics were used, the name(s), route(s) of administration, dosage(s), timing and duration of antibiotics, prophylactic strategy (empirical or culture-guided) and whether other prophylactic measures were applied.

In the third part (eight items), respondents' perceptions of FQ resistance and infectious complications in PB was assessed. Unfortunately, the answers to two questions were not interpretable due to methodological shortcomings. The full questionnaire is available in Supplementary Appendix I.

\section{Statistical analysis}

Descriptive statistical analysis was performed using SPSS version 25.0 (IBM Corp., Armonk, NY, USA). Both completed and partially completed questionnaires were analyzed using the number of completed responses per item as the denominator.

To describe Dutch PB practice, answers to questions on biopsy technique and pre-biopsy patient preparation (part 2) were analyzed on hospital level, i.e. answers of different professionals from the same hospitals were counted once. In case of discrepancies in the answers of urologists from the same hospital, the urology department of the concerning hospital was contacted to reach consensus.

All answers to questions on characteristics of the study population and professionals perceptions on biopsy related infections (part 1 and 3) were analyzed on individual level, i.e. answers of different professionals from the same hospitals were counted separately.

\section{Results}

Demographic characteristics are shown in Table 2. A total of 176 responses were received. Twelve respondents that only answered the demographic questions and three respondents from the Netherlands Antilles were excluded from the analysis. Questionnaires of 161 professionals (38.3\%) were included in the final analyses, providing data on 65 (80.3\%) Dutch hospitals [17]. Three of the professionals only partially answered the other questions. There were 41 (50.6\%) hospitals where more than one urologist completed the questionnaire.

\section{PB techniques}

There was a wide variation in combinations of applied $\mathrm{PB}$ techniques between Dutch hospitals: in total ten different combinations were used (Fig. 1). Schematic TRUSPB was performed in $64(98.5 \%)$ hospitals. TRUSPB was the only method to obtain prostate tissue in 37 (56.9\%) hospitals and was the most common procedure in 21 of the 27 hospitals with additional PB techniques. In four (6.2\%) hospitals, transrectal MRI/TRUS fusion-guided PB was the most used method. Perineal MRI/TRUS fusion-guided PB and transrectal MRI guided PB was most frequently applied in

Table 2 Demographic characteristics

\begin{tabular}{ll}
\hline Parameter & $n(\%)$ \\
\hline Function & $141(87.6)$ \\
Urologist & $20(12.4)$ \\
Residents & \\
Sex & $106(65.8)$ \\
$\quad$ Male & $55(34.2)$ \\
Female & \\
Number of years working in the current position & $37(23.0)$ \\
0-5 years & $52(32.3)$ \\
5-10 years & $72(44.7)$ \\
$\geq 10$ years & \\
Working at & $24(14.9)$ \\
Academic hospital & $136(84.5)$ \\
Peripheral hospital or other institution & $1(0.6)$ \\
\hline Unknown
\end{tabular}




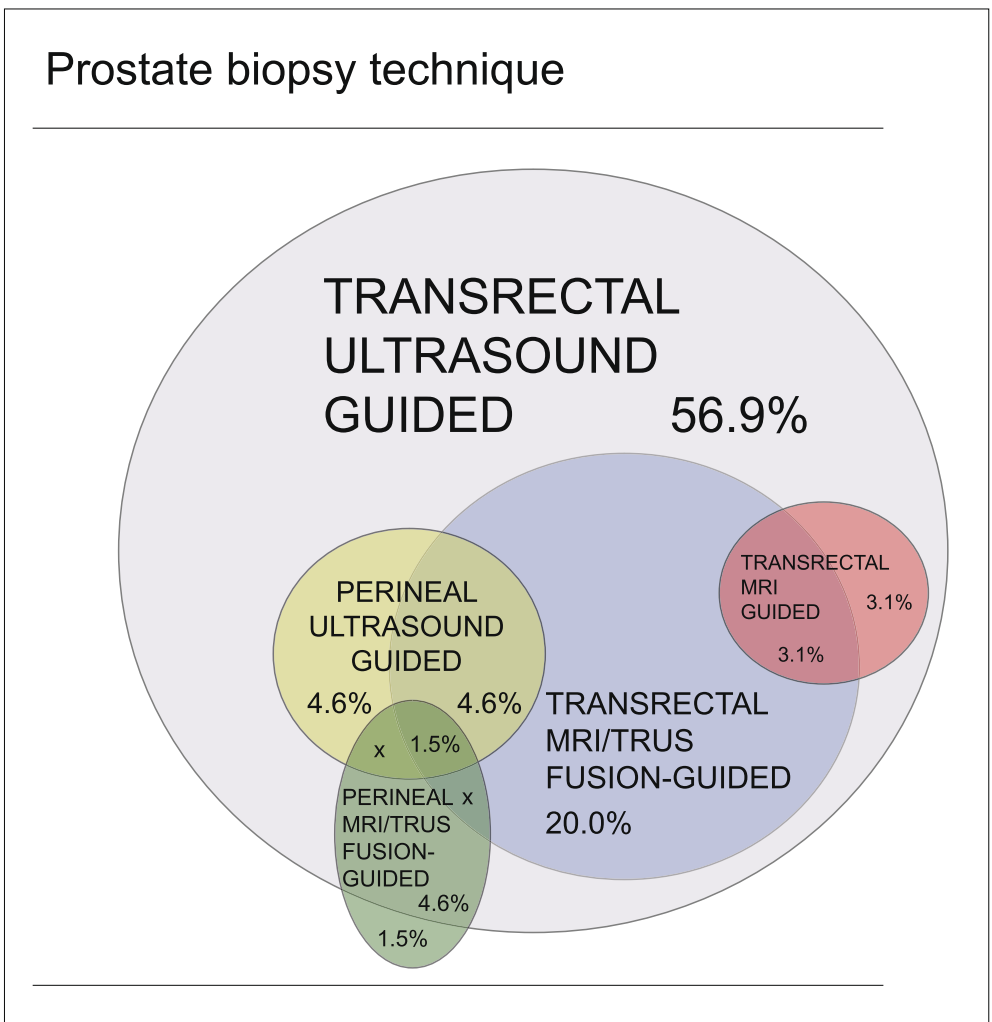

Fig. 1 Variation in combinations of prostate biopsy techniques in the different hospitals. Certain combinations do not exist, these are indicated with $X$

respectively two (3.1\%) and one (1.5\%) hospital(s). Digitally directed PB was occasionally used in 12 (18.5\%) hospitals.

In 57 of the 58 hospitals $(98.5 \%)$ where TRUSPB was the most common procedure, urologists routinely obtained 8-12 cores per biopsy session. In one (1.5\%) hospital, the number of biopsy cores during TRUSPB amounted to $12-16$. In case MRI/TRUS fusion-guided or MRI guided PB was the most common method, there was a wide variation in the number of biopsy cores between hospitals. In four (57.1\%) hospitals, targeted biopsies of mpMRI suspicious lesions were taken in addition to systematic biopsies (12-14 cores per biopsy session) and in three $(42.9 \%)$ hospitals targeted biopsies were taken alone (2-6 cores per biopsy session).

We received one or more responses from all eight academic hospitals in the Netherlands. With regard to PB techniques, almost all academic hospitals also used methods other than TRUSB (87.5\%). In two academic hospitals MRI/TRUS fusion-guided PB and in one academic hospital MRI guided PB was the most used method.

\section{Perioperative antimicrobial prophylaxis}

Oral antimicrobial prophylaxis for transrectal PB was prescribed in all hospitals. There was a wide inter-hospital variation in antibiotic choice, duration and timing combinations: 23 different antibiotic regimens with five different antibiotics were reported. The antibiotics most frequently used were FQ, either alone $(98.5 \%)$ or combined with another antibiotic (1.6\%) (Fig. 2). In case (a combination with) ciprofloxacin was used (84.4\%), a single dose consisted of $500 \mathrm{mg}$ (90.7\%), $750 \mathrm{mg}$ (3.7\%) or 1000 $\mathrm{mg}$ (5.6\%). The duration of the prophylaxis ranged from one pre-biopsy dose to 5 days extended prophylaxis with most hospitals (59.4\%) giving a single dose of antibiotics 1 hour prior to PB (Fig. 2).

In all hospitals, antimicrobial prophylaxis was given empirically according to a standardized protocol. Urologists from four hospitals (6.3\%) reported to use rectal swab cultures prior to $\mathrm{PB}$ in patients at risk for FQ resistance. Other measures reported to prevent infectious complications after PB were screening for urinary tract infection by urine sediment and/or urine culture (3.1\%), washing the biopsy needle with povidone-iodine solution (1.6\%) and the use of laxative suppositories (3.1\%). A rectal enema was included in the preparation in one hospital (1.6\%).

With regard to antimicrobial prophylaxis, no differences between academic and peripheral hospitals were detected nor were there any differences according to regions. The antimicrobial prophylaxis regimens as specified by the 


\section{ANTIMICROBIAL PROPHYLAXIS IN PROSTATE BIOPSIES}

Type of prophylaxis

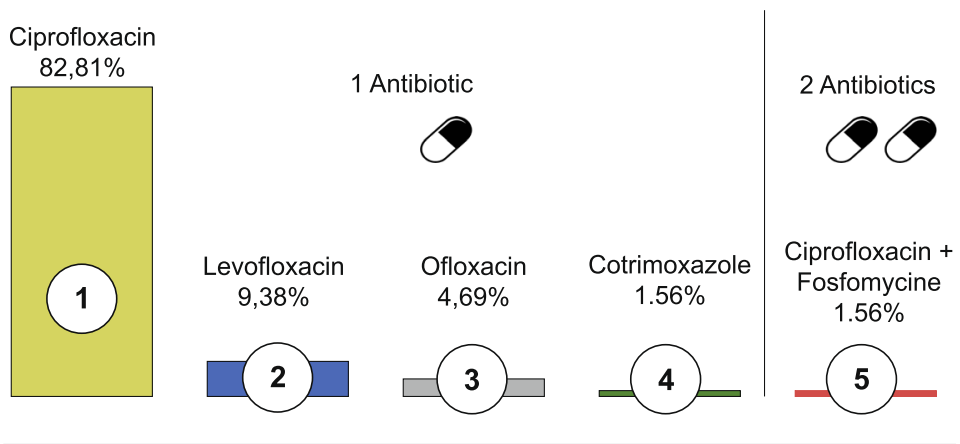

Duration of prophylaxis

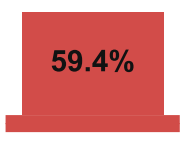

Only once
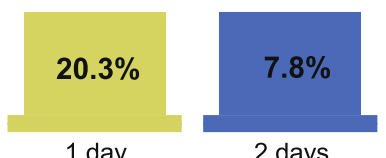

2 days
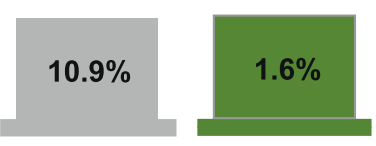

3 days

5 days

\section{Timing of prophylaxis}

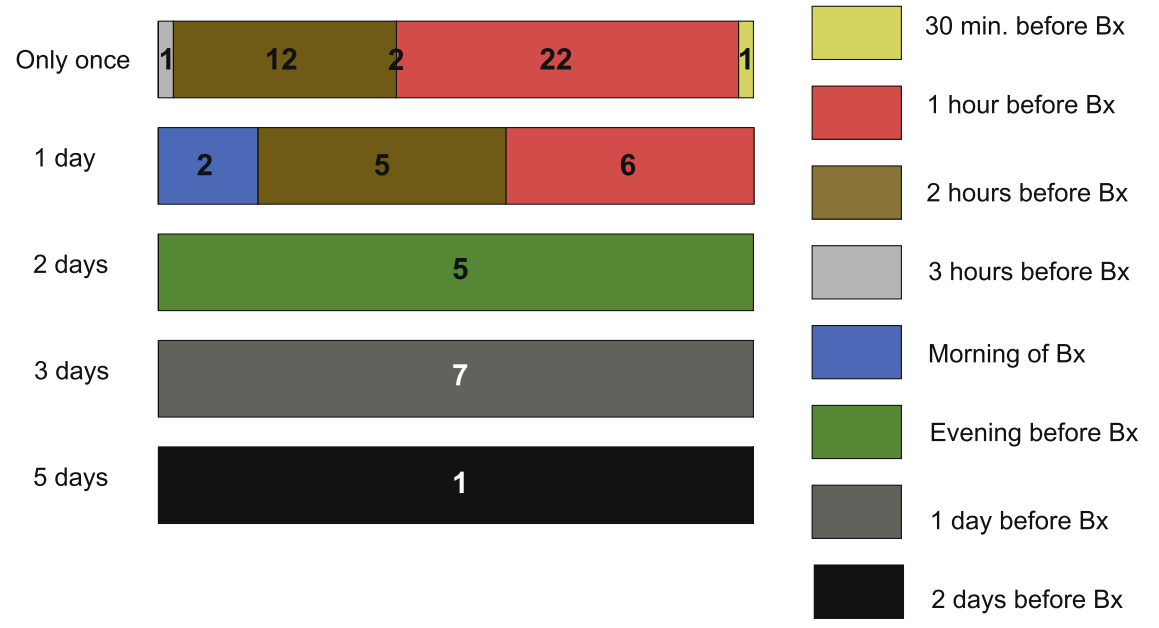

Fig. 2 Variation in antimicrobial prophylaxis in prostate biopsies

respondents on hospital and individual level are described in Supplementary Appendix II.

\section{Urologists' perception regarding antimicrobial prophylaxis in PB}

According to 89 respondents (57.4\%) the degree of infectious complications after $\mathrm{PB}$ in their hospital was stable, while 17 respondents (11.0\%) indicated that they (subjectively) observed a decreasing number and 28 respondents (18.1\%) an increasing number of infectious complications after PB. The other 21 respondents (13.5\%) indicated that they did not know the trend of infectious complications after PB in their hospital.

After stating in our questionnaire that in urological patients the percentage of FQ resistant Gram-negative bacteria has increased from $7 \%$ in 2000 to $19 \%$ in 2017 , we asked professionals if they were aware of this increasing level of FQ resistance [8]. Except for one respondent, all respondents (99.4\%) indicated to be aware of the increasing FQ resistance. However, the degree of FQ resistance was 
assumed to be lower by 52 respondents (33.6\%) and to be higher by four respondents (2.6\%).

A total of 39 respondents (25.2\%) (strongly) agreed with the statement that FQ resistance currently poses a problem in the empirical use of ciprofloxacin alone as prophylaxis around PB. One hundred fourteen respondents $(73.6 \%)$ anticipate future problems in this area (Fig. 3). The preferred solutions of urologists to the increasing resistance for $\mathrm{FQ}$ can be found in Fig. 3. Besides the solutions provided in the questionnaire, urologists also suggested several solutions in the category Other. The most often mentioned 'other' solutions were: 'if necessary, adapt antimicrobial prophylaxis based on local resistance data in consultation with the medical microbiologist or based on evidence-based guidelines' (3.9\%) and 'perform more transperineal biopsies' (3.2\%).

\section{Discussion}

This online survey among Dutch urologists showed a wide variation between hospitals both in $\mathrm{PB}$ techniques and in antimicrobial prophylaxis regimens.

\section{OPINION OF UROLOGISTS}

Opinion of urologists regarding antimicrobial prophylaxis in prostate biopsy

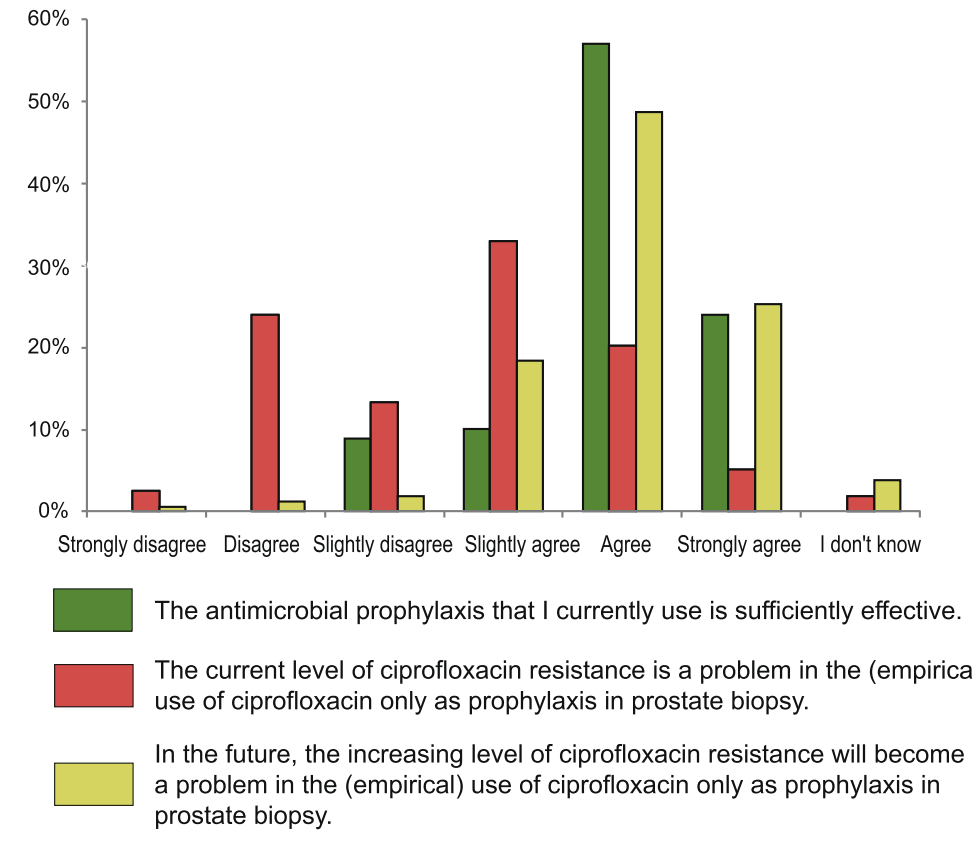

Preferred solution to the increasing resistance for ciprofloxacin
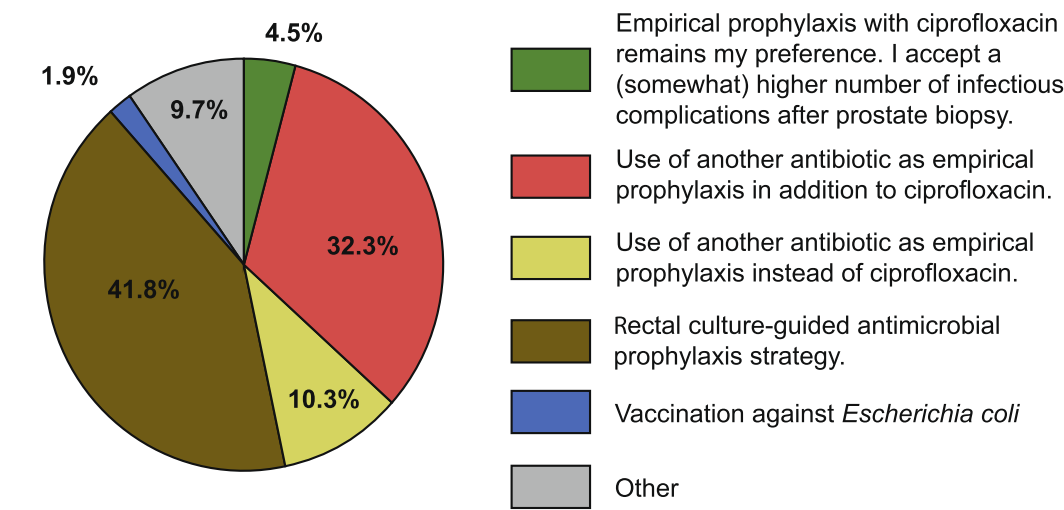

Fig. 3 Urologists' perception of antimicrobial prophylaxis in prostate biopsy 
Our survey showed that systematic TRUSPB with 812 cores per biopsy session was most frequently used (89.3\%), which was in line with the guidelines at that moment [18]. Although our survey was performed before the recently published update of the EAU guidelines, urologists from $41.5 \%$ of the hospitals reported that they already perform MRI guided or MRI/TRUS fusion guided PB [2]. It suggests that (some) urologists, prior to guideline updates, already adjusted their practice patterns based on recent literature [19], which contributes to variation in daily care. In the Netherlands, saturation biopsies are not commonly performed.

Antimicrobial prophylaxis for PB is still dominated by ciprofloxacin monotherapy (84.4\%), reflecting the recommendations in urological guidelines. However, given the rising prevalence of FQ resistance among relevant pathogens, antimicrobial prophylaxis with ciprofloxacin monotherapy is an increasingly doubtful policy. Many Dutch urologists are aware of the increased risk of FQ resistance and about a quarter of all urologists acknowledge rising FQ resistance as a current problem when prescribing antimicrobial prophylaxis. At this moment, only a small number of the Dutch hospitals are opting for a non-FQ based antibiotic regimen or have taken additional measures to address the problem of FQ resistance. We expect, however, that in the (near) future more Dutch hospitals will take measures trying to address rising FQ resistance, since $73.6 \%$ of all urologists anticipate future problems with regard to ciprofloxacin resistance and only $4.5 \%$ responded that ciprofloxacin remains their preference accepting a higher risk of urosepsis.

Furthermore, according to current guidelines the length of antimicrobial prophylaxis should be limited to $<24 \mathrm{~h}$, which is not followed by $20 \%$ of the centers $[4,6,7]$. This deviation from the guidelines is in line with a study of Branch-Elliman et al. in which surgical antimicrobial prophylaxis was continued for $>24 \mathrm{~h}$ in $26.9 \%$ of all patients [20].

It is known that there is a wide variation in antimicrobial prophylaxis regimens internationally and between centers. Prior surveys on pre-prostate biopsy prophylaxis published since 2010 can be found in Supplementary Appendix III [10-15].

Variation in antibiotic choice could be related to a lack of strong evidence, which results in inconsistent and unclear recommendations in urological guidelines $[2,4-7]$. While these guidelines generally recommend antimicrobial prophylaxis in transrectal PB, the choice of regimen, duration and the starting moment are ambiguous.

Moreover, the EAU guidelines leave individual clinicians to determine which patients may benefit from cultureguided prophylaxis [5]. It should be noted that although a recent meta-analysis [21] provided evidence for the use of culture-guided antimicrobial prophylaxis in reducing infectious complications after transrectal $\mathrm{PB}$, a large prospective multicenter trial evaluating the effectiveness of rectal swab culture-guided antimicrobial prophylaxis, cost-effectiveness and optimal implementation is missing, but is currently being performed (NCT03228108).

Finally, the EAU guidelines recommend to use rectal cleansing with povidone-iodine prior to transrectal $\mathrm{PB}$ [5]. This is based on a meta-analysis of six trials including 1373 men that showed that the use of pre-biopsy rectal povidone-iodine preparation in addition to antimicrobial prophylaxis resulted in lower rates of infectious complications [0.58 (0.43 to 0.76$)$; RR $(95 \% \mathrm{CI})]$ [22-27]. However, not a single Dutch urologist reported to use rectal povidone-iodine cleansing prior to PB.

There is no cut-and-dried solution to the increasing resistance against FQ in the context of the risk of post-biopsy infection, which is supported by our finding that Dutch urologists have various preferred solutions to this problem. Although, in our survey, we asked urologists mainly for solutions with in the field of antimicrobial prophylaxis, it is important to note that the solution does not have to be (solely) based on the use of adapted or rectal cultureguided antimicrobial prophylaxis. Various studies found favourable infection rates for transperineal PB compared to TRUSB with similar rates of prostate cancer detection [2, 28-31]. Therefore, transperineal PB is an obvious alternative biopsy approach to avoid infections from FQ resistant bacteria. Our survey showed that transperineal biopsies were performed to some extent in $16.9 \%$ of all Dutch hospitals. In the Netherlands, transperineal biopsy is slow to be implemented in the clinic because of the consequent logistic problems such as the necessity for specialized staff and equipment, MRI capacity, greater labor time, higher costs etc. Moreover, mpMRI is likely to play an increasingly prominent role in the diagnostic pathway of prostate cancer. In the future, mpMRI could possibly reduce the number of biopsy cores and thereby possibly lower (infectious) complication rates without compromising detection rates or avoid $\mathrm{PB}$ in selected patients with negative mpMRI (index lesion PI-RADS $\leq 2$ ) [32, 33].

The main strength of our study is that due to the high response rate $(38.3 \%$ covering $80.2 \%$ of all Dutch hospitals) we were able to get a nationwide impression regarding the current Dutch prostatic biopsy practices.

The most important limitation of our study is that most of the results were analyzed at hospital level in order to obtain a representative picture of the variation in PB practice patterns between Dutch hospitals. Unfortunately, in hospitals where more than one urologist completed the questionnaire $(50.6 \%)$, differences were also found between these intra-hospital urologists with regard to $\mathrm{PB}$ technique (41.5\%) and antimicrobial prophylaxis (48.8\%). However, in all cases the local protocol could be clarified. These intra-hospital differences again emphasize the lack 
of standardization in PB techniques and antimicrobial prophylaxis regimens in the Netherlands even among urologists who work in the same center. On individual level, 41 different antimicrobial prophylaxis regimens were reported instead of the 23 regimens we identified at hospital level (Supplementary Appendix II). In daily clinical practice, the variation is therefore probably even wider than the variation described in this article. Another limitation is that between the performance of our survey and publication of the results, the EAU guideline on prostate cancer [2] has been updated. Therefore, this survey does no longer depict the current international guidelines regarding prostate biopsy technique. This is, however, illustrative for the rapid evolutions in this area. Moreover, two questions were difficult to analyze due to methodological shortcomings and were left out. However, these questions were not critical for our analysis.

\section{Conclusions}

The diversity of the reported prophylactic regimens is likely due to a lack of good evidence. Therefore, there is need for well designed, adequately powered trials of good quality in the field of urological pre-biopsy prophylactic measures. High quality research will result in evidence-based, clearcut recommendations and offers urologists more guidance regarding antimicrobial prophylaxis around $\mathrm{PB}$ in the context of increasing antibiotic resistance. Professionals in daily practice have a need for dynamic, regularly updated guidelines that address changes in procedures, antimicrobial resistance patterns or new scientific insights. This study shows that the lack of standardized, clear guidelines lead to (undesirable) practice variation between health care professionals, which implies that patients in one hospital may receive better care than in another hospital. Moreover, this study shows that in an evolving clinical landscape of PB with changes in procedures, techniques and antimicrobial resistance, current urological guidelines lead to urologists making their own policies, resulting in an over-prescription of prophylactic antibiotics. This is ironically exactly what these guidelines aim to prevent.

\section{Supplementary information}

Supplementary information accompanies this paper at https://doi.org/10. 1186/s12894-020-00592-8.

Additional file 1 Supplementary appendix I Full questionaire. The full online questionnaire that was distributed by the Dutch Association of Urology (DUA) to all its members.

Additional file $\mathbf{2}$ Supplementary file II Antimicrobial prophylaxis regimens on hospital level and as specified by the (individual) respondents. The antimicrobial prophylaxis regimens as specified by the respondents on hospital and individual level are described.

Additional file $\mathbf{3}$ Supplementary file III Prior surveys on pre-prostate biopsy prophylaxis published since 2010. Schematic overview of surveys conducted by others since 2010 about prophylactic measures around transrectal prostate biopsy.

\section{Abbreviations}

DUA: Dutch Association of Urology; EAU: European Association of Urology; FQ: Fluoroquinolones; mpMRI: Multiparametric magnetic resonance imaging; PB: Prostate biopsy; TRUSPB: Transrectal ultrasound guided prostate biopsy; ZonMw: The Netherlands Organisation for Health Research and Development

\section{Acknowledgements}

We thank ZonMw for their financial support.

Consent for publications

Not applicable.

\section{Authors' contributions}

Study design: ST, EKD, RS, AH, EKW, HW, MH, MS. Data collection: ST, MS. Data analysis: ST. Writing the manuscript: ST, MH. Critical review of the manuscript: EKD, RS, AH, EKW, HW, MS. All authors have read and approved the manuscript.

\section{Funding}

This research was funded by The Netherlands Organisation for Health Research and Development (ZonMw), grant number 541001009. ZonMw had no involvement in the design of the study, the collection, analysis and interpretation of data and in writing the manuscript.

\section{Availability of data and materials}

The datasets used and/or analysed during the current study are available from the corresponding author on reasonable request.

\section{Ethics approval and consent to participate}

No individual person's data were collected. All data were anonymized and collected in accordance to the General Data Protection Regulation (GDPR) which standardizes data protection law across all EU countries. Because all data were collected via an anonymous online survey on a voluntary base, approvement of the ethical committee is not required as per local legislation. By accepting the invitation to complete the online survey, all participants provided their informed consent to take part in the study.

\section{Competing interests}

None of the contributing authors have any conflicts of interest, except that this research was funded by The Netherlands Organisation for Health Research and Development (ZonMw), grant number 541001009.

\section{Author details}

${ }^{1}$ Department of Medical Microbiology, Radboud Center Infectious Diseases, Radboudumc, huispost 777, Geert Grooteplein Zuid 10, 6525, GA, Nijmegen, the Netherlands. ${ }^{2}$ Department of Urology, Catharina Hospital, Eindhoven, the Netherlands. ${ }^{3}$ Department of Urology, Canisius-Wilhelmina Hospital, Nijmegen, the Netherlands. ${ }^{4}$ Scientific Center for Quality of Healthcare, Radboud Institute for Health Sciences, Radboudumc, Nijmegen, the Netherlands. ${ }^{5}$ Department of Urology, Radboudumc, Nijmegen, the Netherlands.

Received: 26 June 2019 Accepted: 24 February 2020

Published online: 12 March 2020

\section{References}

1. Volksgezondheidenzorg.info [Updated 12th July 2017. RIVM Bilthoven: [Available from: https://www.volksgezondheidenzorg.info/onderwerp/ prostaatkanker/cijfers-context/huidige-situatie\#!node-prevalentieprostaatkanker.

2. Mottet N, van den Bergh R, Briers E, Cornford P, De Santis M, Fanti S, et al. Guidelines on prostate cancer. Eur Assoc Urol. 2019;65(1):124.

3. Wegelin O, Exterkate $L$, van der Leest M, Kummer JA, Vreuls W, de Bruin PC, et al. The FUTURE trial: a multicenter randomised controlled trial on target biopsy techniques based on magnetic resonance imaging in the diagnosis of prostate Cancer in patients with prior negative biopsies. Eur Urol. 2019; 75(4):582-90.

4. Wolf JS Jr, Bennett CJ, Dmochowski RR, Hollenbeck BK, Pearle MS, Schaeffer AJ, et al. Best practice policy statement on urologic surgery antimicrobial prophylaxis. J Urol. 2008;179(4):1379-90. 
5. Bonkat $G$, Bartoletti RR, Bruyère $F$, Cai $T$, Geerlings $S E$, Köves $B$, et al. EAU Guidelines on Urological Infections 2019. Uroweb. Available from: http:// uroweb.org/guideline/urological-infections/.

6. van Haarst EP, Bootsma AMJ, Elzevier HW, Froeling FMJA, Geerlings SE, Jansen $\mathrm{FH}$, et al. NVU richtlijn: Bacteriële urineweginfecties bij adolescenten en volwassenen. 2009. Available from: https://www.nvu.nl/Portals/_default/ Skins/NVU/DocumentHandlerPublic.ashx?id=817db8b4-e657-40d0-bc20-52 ebc1d286ff\&filename=bijlage\%20C58\%20urineweginfectie\%202009.pdf.

7. Antibioticabeleid SW. SWAB Richtlijn Peri-operatieve profylaxe. 2018.

8. De Greef SC, Mouton JW, Schoffelen AF, Verduin CM. NethMap 2019: consumption of antimicrobial agents and antimicrobial resistance among medically important bacteria in the Netherlands in 2018. RIVM Bilthoven; 2019. Available from: https://www.rivm.nl/sites/default/files/2019-09/ Nethmap\%20Maran\%202019\%20beveiligd.pdf.

9. Van Besien J, Uvin P, Van den Abeele AM, Merckx L. Prevalence, risk factors, and clinical relevance of Fluoroquinolone-resistant organisms in rectal cultures: should we target antibiotic prophylaxis prior to prostate biopsy? Ther Adv Urol. 2016;2016:5392107.

10. Boehm K, Siegel FP, Schneidewind L, Kranz J, Spachmann P, Frank T, et al. Antibiotic prophylaxis in prostate biopsies: contemporary practice patterns in Germany. Front Surg. 2018;5:2.

11. Carlsson S, Bratt O, Stattin P, Egevad L. Current routines for transrectal ultrasound-guided prostate biopsy: a web-based survey by the Swedish urology network. Scand J Urol Nephrol. 2012;46(6):405-10.

12. Davis $P$, Paul $E$, Grummet J. Current practice of prostate biopsy in Australia and New Zealand: a survey. Urol Ann. 2015;7(3):315-9.

13. Hillelsohn JH, Duty B, Blute ML Jr, Okhunov Z, Kashan M, Moldwin R, et al. Variability of transrectal ultrasound-guided prostate biopsy prophylactic measures. Can J Urol. 2012;19(6):6573-7.

14. Smyth LG, Mulvin DW. Antibiotic prophylaxis for transrectal ultrasound biopsy of the prostate in Ireland. Ir J Med Sci. 2012;181(1):33-5.

15. Johnson JR, Polgreen PM, Beekmann SE. Transrectal prostate biopsyassociated prophylaxis and infectious complications: report of a query to the emerging infections network of the infectious diseases society of america. Open Forum Infect Dis. 2015;2(1):ofv002.

16. Grabe M, Bartoletti R, Bjerklund-Johansen TE, Cek HM, Pickard RS, Tenke P, et al. EAU Guidelines on Urological Infections 2015. Uroweb. Available from: https://uroweb.org/wp-content/uploads/19-Urological-infections_LR2.pdf.

17. ZorgkaartNederland. Patiëntenfederatie Nederland. [Available from: https:// www.zorgkaartnederland.nl/uroloog.

18. Mottet N, Bellmunt J, Briers E, van den RCN B, Bolla M, van NJ C, et al. Guidelines on prostate cancer. Eur Assoc Urol. 2015;65(1):124.

19. Rouviere O, Puech P, Renard-Penna R, Claudon M, Roy C, Mege-Lechevallier $F$, et al. Use of prostate systematic and targeted biopsy on the basis of multiparametric MRI in biopsy-naive patients (MRI-FIRST): a prospective, multicentre, paired diagnostic study. Lancet Oncol. 2019;20(1):100-9.

20. Branch-Elliman W, O'Brien W, Strymish J, Itani K, Wyatt C, Gupta K. Association of Duration and Type of Surgical Prophylaxis With Antimicrobial-Associated Adverse Events. JAMA Surg. 2019;154(7):590.

21. Scott S, Harris PN, Williamson DA, Liss MA, Doi SAR, Roberts MJ. The effectiveness of targeted relative to empiric prophylaxis on infectious complications after transrectal ultrasound-guided prostate biopsy: a metaanalysis. World J Urol. 2018;36(7):1007-17.

22. Kanjanawongdeengam $P$, Viseshsindh $W$, Santanirand $P$, Prathombutr $P$, Nilkulwattana S. Reduction in bacteremia rates after rectum sterilization before transrectal, ultrasound-guided prostate biopsy: a randomized controlled trial. J Med Assoc Thail. 2009;92(12):1621-6.

23. Brown RW, Warner JJ, Turner Bl, Harris LF, Alford RH. Bacteremia and bacteriuria after transrectal prostatic biopsy. Urology. 1981;18(2):145-8

24. Melekos MD. Efficacy of prophylactic antimicrobial regimens in preventing infectious complications after transrectal biopsy of the prostate. Int Urol Nephrol. 1990;22(3):257-62.

25. Sharpe JR, Sadlowski RW, Finney RP, Branch WT, Hanna JE. Urinary tract infection after transrectal needle biopsy of the prostate. J Urol. 1982;127(2):255-6.

26. Abughosh Z, Margolick J, Goldenberg SL, Taylor SA, Afshar K, Bell R, et al. A prospective randomized trial of povidone-iodine prophylactic cleansing of the rectum before transrectal ultrasound guided prostate biopsy. J Urol. 2013;189(4):1326-31.

27. Ghafoori M, Shakiba M, Seifmanesh $H$, Hoseini K. Decrease in infection rate following use of povidone-iodine during transrectal ultrasound guided biopsy of the prostate: a double blind randomized clinical trial. Iran J Radiol. 2012;9(2):67-70.
28. Lo KL, Chui KL, Leung CH, Ma SF, Lim K, Ng T, et al. Outcomes of transperineal and transrectal ultrasound-guided prostate biopsy. Hong Kong Med J. 2019;25(3):209-15.

29. Xue J, Qin Z, Cai H, Zhang C, Li X, Xu W, et al. Comparison between transrectal and transperineal prostate biopsy for detection of prostate cancer: a meta-analysis and trial sequential analysis. Oncotarget. 2017;8(14): 23322-36.

30. Huang GL, Kang CH, Lee WC, Chiang PH. Comparisons of cancer detection rate and complications between transrectal and transperineal prostate biopsy approaches - a single center preliminary study. BMC Urol. 2019;19(1):101.

31. Grummet J. How to biopsy: Transperineal versus Transrectal, saturation versus targeted, What's the evidence? Urol Clin North Am. 2017;44(4):525-34.

32. Venderink $W$, van Luijtelaar $A$, van der Leest M, Barentsz JO, Jenniskens SFM, Sedelaar MJP, et al. Multiparametric magnetic resonance imaging and followup to avoid prostate biopsy in 4259 men. BJU Int. 2019:124(5):775-84.

33. Kasivisvanathan V, Rannikko AS, Borghi M, Panebianco V, Mynderse LA, Vaarala $\mathrm{MH}$, et al. MRI-targeted or standard biopsy for prostate-Cancer diagnosis. N Engl J Med. 2018;378(19):1767-77.

\section{Publisher's Note}

Springer Nature remains neutral with regard to jurisdictional claims in published maps and institutional affiliations.
Ready to submit your research? Choose BMC and benefit from:

- fast, convenient online submission

- thorough peer review by experienced researchers in your field

- rapid publication on acceptance

- support for research data, including large and complex data types

- gold Open Access which fosters wider collaboration and increased citations

- maximum visibility for your research: over $100 \mathrm{M}$ website views per year

At BMC, research is always in progress.

Learn more biomedcentral.com/submissions 